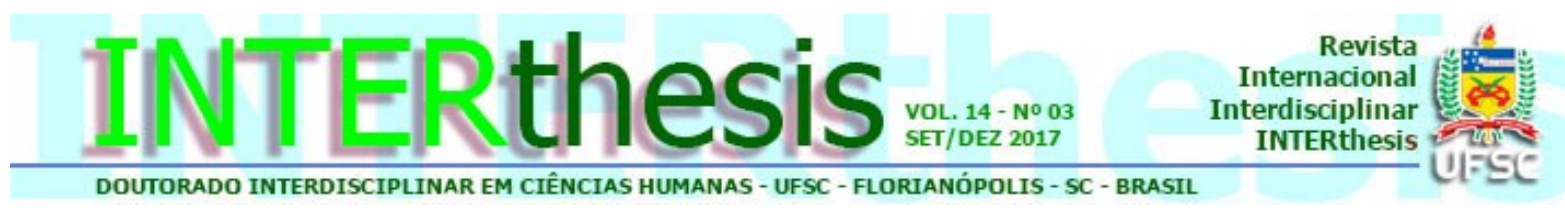

\title{
A OIKONOMIA NAS EPÍSTOLAS DE PAULO: NOTAS SOBRE A "HERMENÊUTICA" DE AGAMBEN
}

Rafael Venturini ${ }^{1}$

\section{Resumo:}

Acompanhando a reconstrução da origem do conceito teológico de oikonomia, que Giorgio Agamben oferece na obra O Reino e a Glória: Uma Genealogia Teológica da Economia e do Governo: Homo sacer II, 2 (2011), o artigo propõe uma releitura dos trechos nos quais, em suas cartas às igrejas, o apóstolo Paulo utiliza o termo grego. Essa releitura confirma a proposição geral do filósofo italiano, de que a compreensão da oikonomia como uma "administração" dos homens e das coisas, como um paradigma gerencial, não parece ter sofrido alterações semânticas expressivas nos escritos de Paulo e na linguagem corrente entre os cristãos até o fastígio do Império Romano. Não obstante, tal releitura acaba por indicar fragilidades significativas em O Reino e a Glória, as quais podem ser constatadas tanto pelo leitor não especializado como pelos estudiosos de Agamben nos campos da filosofia, da teologia e da economia política. Essas notas sobre a obra de Agamben são, por fim, uma tentativa de estabelecer um diálogo com outros textos recentemente publicados no Brasil sobre o autor.

Palavras-chave: Oikonomia. Epístolas de Paulo. Hermenêutica. Giorgio Agamben. O Reino e a Glória.

\section{INTRODUÇÃO}

De Lutero a Kierkegaard e Nietzsche ou, ainda, de Agostinho a Heidegger e Taubes, o leitor das Epístolas do apóstolo Paulo parece ser repetida e ousadamente levado a interrogar a teologia e a filosofia de seu tempo. Para Gignac (2009, p. 14), quem defende essa tese, "sempre é verdade que se considerou Paulo como um mestre a ser pensado, um texto apto a provocar um choque e a alimentar a reflexão. E que ele é novamente redescoberto, após um eclipse temporário".

Talvez por isso, conforme documenta Harink (2010), a referência a Paulo de Tarso tem sido frequente na reflexão de alguns filósofos europeus nesse início de século. E, dentre essas releituras dos textos paulinos, devem ser destacadas aqui considerando sua recepção no Brasil - a do esloveno Slavoj Žižek, a do francês Alain Badiou e, notadamente, a do italiano Giorgio Agamben.

\footnotetext{
${ }^{1}$ Economista e Mestre em Política Social pela Universidade Federal do Espírito Santo. Técnico em Informações Geográficas e Estatísticas do Instituto Brasileiro de Geografia e Estatística em Cariacica, ES, Brasil. E-mail: rafaelventurini.t@gmail.com
} 
Sendo tão vultosas as possibilidades de tal resgate, essas tentativas, todavia, parecem ter sido erigidas sobre uma "hermenêutica" demasiado tática dos escritos do apóstolo. Como percebido por Kerekes (2015) e Ratajczak e Zawisza (2015), essas interpretações partem, evidentemente, menos de fundamentadas considerações teológicas do que de urgentes impulsos de ruptura com os limites do pensamento contemporâneo, dito "pós-moderno". Ma proprio qui sta il busillis.

Mesmo que, em um primeiro momento, seja possível ser condescendente com a "hermenêutica" dos autores dessa ousada empreitada, em um segundo momento os leitores não deveriam condescender consigo mesmos. Quando, por exemplo, nos livros de Agambem, textos e fatos fundamentais da história do cristianismo são reinterpretados sob vislumbres de um agir com referências metafísicas, como poderia esse autor ser avaliado por leitores desproporcionalmente mais habituados com a crítica social do que com teologia? Poucos leitores, aliás, parecem encontrar o olhar do imperador Constantino I em Giorgio Agamben, mas o filósofo italiano, por vezes, enxerga as corporações religiosas como vanguarda intelectual, moral e política dos tempos. Veja-se, sobre isso, como o catolicismo romano é ingenuamente retratado e mesmo chamado a um maior protagonismo histórico em Agamben (2013, 2015 e 2016, passim).

Tendo um escopo diminuto, o texto que segue examina um dos principais trabalhos de Agamben (dentre os acima citados, o autor que mais frequentemente recorre a Paulo e comenta questões teológicas e filosóficas que este suscitou ao longo do tempo), de modo a explorar algumas de suas virtudes e fragilidades. Essencialmente, tal esforço dedica-se a dar novas notas sobre a "teologia econômica" que Agamben apresenta a partir de Paulo em O Reino e a Glória. Não obstante, o artigo também convida os leitores de O Tempo que Resta - segundo o próprio autor, em conversa pessoal com Assmann (2015, p. 6), "o livro que mais gostou de escrever" -, bem como de outras leituras das Epístolas, para um olhar ainda mais radical do texto bíblico, é dizer, mais próximo de sua Raiz.

\section{METODOLOGIA}

Como se sabe, com a publicação original de Il Regno e la Gloria, em 2007, Agamben apresentou os resultados de uma longa investigação sobre as modalidades e razões do poder ter assumido, no Ocidente, a forma de uma 
oikonomia (termo que será tratado em detalhes mais adiante e que, de forma sucinta, refere-se a uma "administração" dos homens e das coisas). A condução de seu texto foi entregue à hipótese de que a preparação do dogma católico da trindade - transcorrida entre os séculos II e V da era cristã -, por apresentar a oikonomia sob um formato paradigmático converte-se em terreno favorável à observação do funcionamento da máquina governamental moderna.

Como já esboçado, neste artigo a ênfase recai sobre a "teologia econômica" e os trechos de particular interesse teológico e linguístico de seu desenvolvimento, dispostos no capítulo intitulado "O Mistério da Economia". Ali, quando começa sua genealogia do conceito teológico de oikonomia, o autor contesta a noção de que o apóstolo Paulo teria sido o primeiro a atribuir um significado transcendente ao termo oikonomia.

É incorreto, portanto, dizer, como Milovic (2009, p. 110), em um dos primeiros textos publicados no Brasil que fazem menção à obra $O$ Reino e a Glória, que segundo esta "Paulo é o primeiro que articula uma significação teológica da economia". Se, com o "trinitarianismo econômico" de escritores como Hipólito (c. 170-235 d.C) e Tertuliano (c. 155-230 d.C), por exemplo, o termo refere-se a uma "articulação da vida e atividade divinas", a proposição geral de Agamben é justamente que sua utilização nas cartas do apóstolo às igrejas não corresponde a uma transformação do sentido original da palavra, mas a uma "extensão analógica de sua denotação".

Oferecendo uma interpretação independente dos textos bíblicos que aparecem naquele segundo capítulo de Agamben, procura-se evidenciar que, embora essa proposição do autor seja substancialmente adequada, sua interpretação textual de alguns dos trechos de Paulo é frágil.

Isso é percebido à luz de uma abordagem que considera mais detidamente o conteúdo mesmo das Epístolas através de diferentes versões das Escrituras - o que o autor, aparentemente, não faz. A despeito de que Agamben costumeiramente traduza para $\mathrm{o}$ italiano diretamente de um texto grego original $\mathrm{e}$, conquanto a Vulgata Latina seja mencionada por ele em algumas comparações esparsas, é digno de nota que Agamben também costumeiramente não se atenha a indicar e cotejar as traduções ou os manuscritos gregos por ele utilizados. As aludidas dificuldades, portanto, parecem derivar de um lapso metodológico - seja de investigação ou de 
exposição - que é caro à natureza do objeto de estudo e do nível de profundidade a que o autor pretende alcançar no mesmo.

$\mathrm{Na}$ revisão que segue, optou-se por citar os versículos bíblicos em sua tradução ao português de João Ferreira de Almeida, versão Corrigida e Revisada Fiel ao Texto Original. Não obstante, para a interpretação textual foi realizada uma comparação com outras quatro versões, quais sejam, a King James, a Reina-Valera, a Vulgata e a Bíblia de Jerusalém. Os trechos entre chaves são a transliteração em caracteres latinos sem acentos fonéticos do original grego do texto majoritário do Novo Testamento, disposto no Textus Receptus de Stephanus (1877).

\section{DA MODERNA ECONOMIA POLÍTICA À OIKONOMIA ANTIGA}

Antes de tratar dos escritos de Paulo, importa refazer uma rota da travessia linguística que a oikonomia dos antigos gregos fez até a "economia política" dos modernos. Invertendo-se o sentido cronológico dessa história, ver-se-á que, se Agamben (2011, p. 301) tem razão quando afirma que a oikonomia "desaparece da linguagem teológica do Ocidente latino durante a Idade Média", é impreciso afirmar, não obstante, que, quando o termo ressurge no século dezoito, latinizado como oeconomia, "ele parece surgir ex novo, já formado na cabeça dos philosopes e dos économistes, sem nenhuma relação essencial com a economia clássica ou com o próprio passado teológico". Naturalmente, é Aristóteles quem exige, aqui, seu lugar.

Com a publicação de Eléments d'Economie Politique Pure, em 1874, pode-se dizer que o economista Léon Walras encerra a tradição segundo a qual os títulos e subtítulos das grandes obras de seu campo do saber faziam quase necessariamente menção ao termo "economia política".

Deixando-se de lado alguns contraexemplos - como o célebre Wealth of Nations (1776), de Adam Smith, que, sem embargo, utiliza, no texto, o termo political oeconomy - momentos fundamentais dessa tradição são Das Kapital: Kritik der Politischen Ökonomie (1867), de Marx; os Principles of Political Economy (1820), de Thomas Malthus; David Ricardo e seus Principles of Political Economy and Taxation (1817); e James Steuart com An Inquiry into the Principles of Political Economy, 
Being an Essay on the Science of Domestic Policy in Free Nations (1767). ${ }^{2}$

Tal tradição, aliás, guarda suas origens no próprio país de Walras e muito antes de Jean Baptiste de Say e seu Traité d'Économie Politique (1803) ou, ainda, do artigo "Oeconomie Politique" (1765), publicado no volume onze de l'Encyclopédie, por Diderot, e que aparentemente fala pouco dos temas que depois viriam a ser estudados de modo especial pela "economia política". Em rigor, o autor normando de Traicté de l'Economie Politique (1615), Antoine Montchrestien (1575-1621), parece ter sido o primeiro a denominar e intitular dessa forma o conjunto de análises e prescrições que oferecia ao enriquecimento de um estado moderno.

Na extensa História da Análise Econômica, em que comenta esse último fato, Schumpeter (1964, p. 212) classifica o Traicté como "uma realização medíocre, que carece totalmente de originalidade", tendo no título que carrega "seu único mérito".

Mas não são fortuitas as motivações dessa influente opção léxica que, como mostram Teixeira (2000) e McCloskey (2016), atravessou todo o mercantilismo e a "escola clássica" do pensamento econômico, sendo abandonada em favor de economics apenas no fim do século dezenove, com Alfred Marshall. A principal, senão única evidência de tais motivações são as referências numerosas de Montchrestien ao pensamento aristotélico.

Nesse mesmo sentido, Jean Jacques Rousseau, ao escrever o artigo "Economie ou Oeconomie (Moral et Politique)" do quinto volume da l'Encyclopédie, publicado em 1755, faz referência a Aristóteles. Rousseau, de fato, começa esse texto com a etimologia grega da palavra em questão e a distinção das duas acepções que a mesma apresentava em seu tempo: como "économie générale, ou politique" e "économie domestique, ou particulière". Esse artigo seria publicado separadamente em Genebra, no ano de 1758, já com o título de Discours sur I'Économie Politique.

Assim, quando se considera essa presença da referência clássica em Montchrestien e, sobretudo, em Rousseau, não parece ser possível consentir que o termo "economia política" dos modernos "parece surgir ex novo", "sem nenhuma relação essencial com a economia clássica". Desta falaremos agora.

Na Política, Aristóteles (1944, v. 21, livro I, seção 1256b) dizia que os "bens

\footnotetext{
2 Ao menos nas obras de Smith, Malthus e Marx, aliás, é interessante ver como muitas reflexões típicas de economistas, filósofos e teólogos aparecem continuamente entrelaçadas umas nas outras. John Locke (1632-1704), antes deles, deu mostras ainda mais firmes desse entrelaçamento.
}

R. Inter. Interdisc. INTERthesis, Florianópolis, v.14, n.3, p.32-49 Set.-Dez. 2017 
são uma coleção de ferramentas para o administrador da casa e o estadista", pouco depois de assentar que "a economia (oikonomikês) deve buscar antecipar a provisão daqueles bens, passíveis de acumulação, que são necessários à vida (zoèn) e úteis para a comunidade da cidade (póleos) ou da casa (oikías)". Ora, é bem sabido que, para Aristóteles, ao passo que a política é a ciência mestra da organização social e da felicidade dos homens, a economia restringe-se a organizar o uso da propriedade familiar. Agamben (2011, p. 38) comenta, aliás, que uma "oikonomia politikë" seria "um verdadeiro nonsense na perspectiva de Aristóteles".

Literalmente, o vocábulo grego oikonomia (oikovopía, formado por oĩkos,

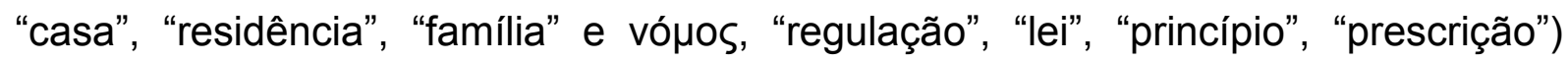
expressa a ideia de "administração da casa". Na Grécia dos séculos IV e III a.C., conforme encontra-se em Aristóteles e na poesia de Xenofonte, oikonomia identificava o caráter administrativo ou gerencial de relações domésticas orientadas segundo uma ordem funcional. São relações econômicas, por exemplo, aquelas entre o senhor e o escravo, um chefe de família (despótes) e sua casa e mesmo um servidor e suas ferramentas de trabalho.

Pelo fato da pólis constituir-se primeiramente de famílias, Aristóteles (1944, v. 21, livro I, seção 1255b) postula já no início da Política o estatuto da oîkos em relação à cidade-estado clássica. "Administração da casa (oikonomikè) é monarquia", escreve, dado que "toda casa é administrada por um só governante". Noutro sentido, "a política (politikè) é o governo de homens livres e iguais". Para o Estagirita, com efeito, - e isso já havia sido notado por Agamben no início das investigações de Homo sacer - a oikonomia propriamente dita, enquanto arte de governar a atividade doméstica e reproduzir a simples vida natural (zoè) é não apenas distinta, mas guarda certa oposição com a política e a filosofia. Diante destas ocupações "importantes" e "dignas" da vida qualificada (bíos) a prática gerencial do instrumentum vocalis, do trabalho escravo - base da sociedade grega ao tempo de Aristóteles - apresenta-se apenas como um estorvo, o qual pode ser delegado aos próprios escravos por parte dos cidadãos que detêm a capacidade para tanto. Escreve ele:

A ciência do senhor é a ciência de empregar escravos - pois a função do senhor não consiste em adquirir escravos, mas em empregá-los. Esta ciência, contudo, não tem importância ou dignidade especial: o senhor deve saber como dirigir as tarefas que o escravo deve saber como executar. Portanto, todas as pessoas ricas o suficiente para evitar preocupações 
pessoais têm um gerente que toma esse serviço, enquanto eles ocupam-se na política ou na filosofia. (ARISTÓTELES, 1944, v. 21, livro I, seção 1255b).

Em O Reino e a Glória, defende-se que esse paradigma gerencial da oikonomia não parece ter sofrido alterações semânticas expressivas pelo menos até o fastígio do Império Romano. Citando uma passagem de Cícero (106-43 a.C) e das Recordações de Marco Aurélio (121-180 d.C), dentre outros, Agamben (2011, p. 34) dirá que "a consciência do sentido doméstico originário do termo nunca se perdeu". Sem dúvidas, o fato de que Paulo (deve-se lembrar, um judeu nascido na província romana da Cilícia), tenha vivido e realizado viagens missionárias em diferentes regiões sob o domínio dos césares ao longo do século I d.C. - ou seja, o mundo helenizado em um período posterior à definição básica de oikonomia e anterior ao uso semântico comum, por autores latinos, no segundo século - torna presumível que ele estivesse familiarizado com o termo e seu significado básico. E não apenas ele, aliás, mas também seu contemporâneo Lucas, que the era um amigo próximo (obiobi: No décimo sexto capítulo do evangelho de Lucas, pode-se lembrar, o substantivo oikonómos ("mordomo") e alguns derivados sufixais são referenciados várias vezes. O capítulo abriga a parábola em que Cristo ensina aos discípulos que "nenhum servo pode servir dois senhores", "não podeis servir a Deus e às riquezas". Seus três primeiros versículos são de especial importância aqui:

\begin{abstract}
E dizia também aos seus discípulos: Havia um certo homem rico, o qual tinha um mordomo [oikonomon]; e este foi acusado perante ele de dissipar os seus bens. E ele, chamando-o, disse-lhe: Que é isto que ouço de ti? Dá contas da tua mordomia [oikonomias], porque já não poderás ser mais meu mordomo. E o mordomo disse consigo: Que farei, pois que meu senhor me tira a mordomia? Cavar, não posso; de mendigar, tenho vergonha. (BÍBLIA, 2007, p. 1126-1127).
\end{abstract}

Isoladamente, os versos oferecem algum suporte para a suposição de que, por volta dessa época, o sentido original do termo era corrente entre os cristãos. Não obstante, como é razoável, Agamben prescinde de digressões como essa e apresenta sua proposição geral depois da consideração de seis excertos paulinos, os quais estão dispostos no item abaixo em cinco subitens.

\title{
4 A OIKONOMIA NAS EPÍSTOLAS DE PAULO
}

\subsection{Coríntios 9:16-17}

De antemão importa dizer que, apesar de algumas versões bíblicas estarem 
mais próximas do sentido literal do verbo oikonomen e apresentarem tanto para essa passagem como em outras a palavra "mordomia", a opção dos tradutores por "dispensação" é francamente predominante, seja em 1 Coríntios ou nas demais cartas às igrejas, como se verá adiante. ${ }^{3}$ Diz o texto:

Porque, se anuncio o evangelho, não tenho de que me gloriar, pois me é imposta essa obrigação; e ai de mim, se não anunciar o evangelho! E por isso, se o faço de boa vontade, terei prêmio; mas se de má vontade, apenas uma dispensação me é confiada [oikonomian pepisteumai]. (BÍBLIA, 2007, p. 1243).

Dele depreende-se, simplesmente, que, não estivesse Paulo bem disposto a cumprir essa obrigação, que Ihe foi atribuída divinamente, ela seria apenas uma incumbência ordinária - e sem gratificação, como aquela confiada a um mordomo por seu senhor. Assim, em conformidade com a proposição geral de Agamben, nada há neste primeiro texto de distintivo quanto ao uso básico do termo oikonomia. Contudo, deve ser sublinhado o fato de que, ao interpretá-lo, o filósofo estranhamente identifica a própria "obrigação" (que, nesse caso, pode ou não ser cumprida de "boa vontade") à "dispensação" (ou seja, a segunda dessas opções).

O sentido aqui é perspícuo e a construção com pisteuo não permite dúvida: oikonomia é a missão (como na Septuaginta, les, 22,21) que foi confiada a Paulo por Deus; por isso Paulo não age livremente, como um negotiorum gestio [gestão de negócios], mas segundo um vínculo fiduciário (pistis) como apostolos ("enviado") e oikonomos ("administrador encarregado"). A oikonomia é aqui algo que é confiado; portanto, é uma atividade e um encargo, e não um "plano salvífico" que diz respeito à mente ou à vontade divina. (AGAMBEN, 2011, p. 36).

Em outra ocasião, Agamben (2011, p. 51) reafirmará que "em Paulo, a economia era a atividade desenvolvida para revelar ou realizar o mistério da vontade ou da palavra de Deus". Mas, em que pese a própria ambivalência de pisteuo ("confiar algo a alguém", "crer"), ao contrário do que pretende o autor italiano, enquanto apóstolos, e não como oikonómos, Paulo executa por vontade própria um mandato que é divino - não ordinário ou doméstico - e que, ademais, Ihe redundará em uma recompensa que extrapola o âmbito material. Há aqui, então, como é necessariamente frequente nos escritos paulinos, uma tensão entre a ordem espiritual e a ordem secular, o que garante a possibilidade mesma dessa extensão

\footnotetext{
${ }^{3}$ Pode ser que a opção de Jerônimo tenha sido decisiva para isso. Harden (1921, p. 37) confirma, em seu Dicionário do Novo Testamento da Vulgata, que dispensatio é a principal equivalente dessa versão para oikonomia. Por sua vez, Agamben (2011, p. 33-34) comenta que, no âmbito da retórica grega, oikonomia era utilizada de modo técnico para designar a distribuição ordenada dos elementos de uma oração ou tratado. Na retórica ciceroniana, oikonomia seria traduzida como dispositio e, algum tempo depois, sobrepuseram-se no idioma dispositio e dispensatio.
} 
analógica dos sentidos envolvidos. Apesar disso, como se verá à frente, chegando ao fim de seu exame das Epístolas Agamben vai retomar esse argumento e expandi-lo de modo temerário. Por ora, seguem-se os demais trechos em análise.

\subsection{Timóteo 1:3-4}

No segundo texto (cuja interpretação adequada de oikonomia, segundo Agamben, também seria a de "atividade" e "encargo" confiado), dirigindo-se ao jovem Timóteo Paulo diz:

Como te roguei, quando partia para a Macedônia, que ficasses em Éfeso, para advertires a alguns, que não ensinem outra doutrina, nem se deem a fábulas ou a genealogias intermináveis, que mais produzem questões do que edificação de Deus [\{oikonomian ou oikodomian\} theou], que consiste na fé; assim o faço agora. (BíBLIA, 2007, p. 1293).

Nessa passagem, o texto grego apresenta as variantes oikonomia e oikodomía ("edificação", "construção arquitetônica"). Ambos os termos são comumente utilizados por Paulo, mas nesse contexto - como em outros textos que serão vistos à frente (Romanos 14:19; 1 Coríntios 14:3; 2 Coríntios 12:19; Efésios 4:16 etc.) - o segundo deles parece ajustar-se mais perfeitamente. De fato, é ele quem aparecerá em todas as versões aqui aferidas. Trata-se, pois, de outra extensão analógica da denotação original, e o termo evoca simbolicamente algo como o desenvolvimento da obra de santificação, que é mediante a fé em Deus.

\subsection{Colossenses 1:24-25}

Regozijo-me agora no que padeço por vós, e na minha carne cumpro o resto das aflições de Cristo, pelo seu corpo, que é a igreja; da qual eu estou feito ministro [diakonos] segundo a dispensação [oikonomian] de Deus, que me foi concedida para convosco, para cumprir a palavra de Deus; (BÍBLIA, 2007, p. 1283).

Dentre todos os excertos, esse é certamente o de mais imediata compreensão. Uma leitura mais literal dos termos entre colchetes permite ver que ele e sua continuação no capítulo expressam que, na "administração" ou "mordomia" (oikonomia) da obra de Deus, para que cumprisse Sua palavra anunciando o evangelho, as boas novas da salvação em Cristo, Paulo foi constituído "criado" da igreja (diákonos), por quem padece. No passo seguinte, porém, aparecem algumas dificuldades para Agamben.

\subsection{Efésios 1:9-10 e 3:8-9}

R. Inter. Interdisc. INTERthesis, Florianópolis, v.14, n.3, p.32-49 Set.-Dez. 2017 
Aparentemente diferenciando-se um pouco dos demais, os dois próximos trechos analisados pelo autor correlacionam a revelação do "mistério" da vontade de Deus, que previamente planejara resgatar a humanidade por meio de Cristo, ao cumprimento dessa vontade - enquanto uma "dispensação" - na primeira vinda de Cristo. Escreve Paulo aos irmãos em Éfeso:

Descobrindo-nos o mistério [mysterion] da sua vontade, segundo o seu
beneplácito, que propusera em si mesmo, de tornar a congregar em Cristo
todas as coisas, na dispensação da plenitude dos tempos [oikonomian tou
pleromatos ton kairon], tanto as que estão nos céus como as que estão na
terra; (BÍBLIA, 2007, p. 1271).

Também nesse caso, a oikonomia expressa a execução de um ato segundo uma finalidade. Por "plenitude dos tempos", cabe entender o momento em que a profecia da vinda e ministério salvífico do Messias devia cumprir-se (ver o capítulo 9 do profeta Daniel), tal como encontramos na carta de Paulo aos Gálatas 4:4 ("mas, vindo a plenitude dos tempos, Deus enviou seu Filho, nascido de mulher, nascido debaixo de lei"). Nesse sentido, a "economia da plenitude dos tempos" parece expressar a eleição divina, em seu caráter oportuno e preciso, da ocasião em que Cristo foi enviado. Agamben (2011, p. 37), porém, vê aqui uma "situação mais complexa" e, embora afirme que "também nesse caso oikonomia significa simplesmente uma atividade", ele apresenta certa hesitação ao considerar que "não é indiferente" que Paulo apresente o cumprimento da promessa divina como uma "tarefa de administração doméstica". A hesitação fica ainda mais pronunciada quando o texto seguinte, dois capítulos à frente na mesma epístola, é citado e comentado pelo autor. Escreve Paulo:

A mim, o mínimo de todos os santos, me foi dada esta graça de anunciar entre os gentios, por meio do evangelho, as riquezas incompreensíveis de Cristo, e demonstrar a todos qual seja a comunhão do mistério [koinonia tou mysteriou], que desde os séculos esteve oculto em Deus, que tudo criou por meio de Jesus Cristo; (BÍBLIA, 2007, p. 1273).

Noutro sentido, a tradução citada pelo filósofo e seu comentário são estes:

"A mim, o menor de todos os santos, foi-me concedida esta graça de anunciar aos gentios a incognoscível riqueza de Deus e levar à luz a oikonomia do mistério, oculto durante séculos em Deus..." [...] A "oikonomia do mistério" é com toda evidência, uma contradição com relação à expressão usada em Cl 1,25 ("a oikonomia de Deus, aquela que me foi encomendada para cumprir a palavra de Deus e o mistério escondido por séculos"), e também aqui nada autoriza substituir o sentido de "realização, administração" por aquele não atestado de "plano salvífico". (AGAMBEM, 2011, p. 37). 
Dado o acima exposto, fica evidente que o texto citado por Agamben, bem como sua interpretação, encerram um impasse desnecessário à defesa de sua proposição geral, a qual, ademais, será adequadamente corroborada no passo seguinte de sua análise.

\subsection{Coríntios 4:1-2}

Para o último texto, o autor volve à primeira carta estudada, na qual Paulo escreve: "Que os homens nos considerem como ministros [hyperetas] de Cristo, e despenseiro dos mistérios de Deus [oikonomos mysterion theou]. Além disso, requer-se dos despenseiros que cada um se ache fiel [pistos]" (BÍBLIA, 2007, p. 1238). Retomando o que foi dito acerca de Colossenses 1:24-25, uma leitura ao pé da letra ofereceria os termos "servidores" [hyperetas] de Cristo e "mordomos" [oikonomos] dos mistérios de Deus. Temos, pois, uma aproximação reflexiva de oikonomos com hyperetas que aprofunda a extensão analógica do sentido propriamente doméstico dos dois termos. Por seu turno, Agamben (2011, p. 37) parece retomar a ideia da oikonomia como sendo o próprio "encargo confiado" em sua natureza espiritual - ideia essa cuja formulação procede a sua leitura de 1 Coríntios 9:16-17 (tratado no subitem 1) - e postula que "aqui, a relação entre oikonomia e mistério é evidente: trata-se de ser fiel ao encargo de anunciar o mistério da redenção que estava oculto na vontade de Deus e agora chega à sua realização". 4' De qualquer maneira, até este ponto a presente revisão da análise do autor permite concluir que sua posição geral é correta, ou seja, não há um uso particular do termo oikonomia nos textos paulinos; por oikonomia Paulo não se refere ao "plano salvífico" em si, mas a um conjunto de atividades que realizam esse "mistério" que havia sido anunciado profética e tipologicamente ao homem nos tempos do Antigo Testamento.

\section{OÎKOS, EKKLESÍA E PÓLIS}

Ao fechar seus argumentos sobre a oikonomia em Paulo, Agamben convida o

\footnotetext{
${ }^{4}$ Deve-se salientar que Paulo não menciona aqui, como no outro texto da carta, o "encargo" ou "obrigação" de pregar o evangelho, tampouco denota essa tarefa como uma oikonomia. Ao contrário, como sugerimos anteriormente, aceitar todos os contornos de tal posição ou tal posição em todos os textos citados por Agamben exigiria, no limite, ignorar a tensão existente entre o apóstolos ("enviado" por Deus) e o oikonómos ("mordomo", "administrador"), a esfera do sagrado e a do secular - o que é imprescindível para proposição de que há uma "extensão analógica".
}

R. Inter. Interdisc. INTERthesis, Florianópolis, v.14, n.3, p.32-49 Set.-Dez. 2017 
leitor à outra perspectiva do tema. Poucos parágrafos depois de ter afirmado não ser indiferente que a representação do cumprimento das promessas divinas apareça em alguns momentos como uma "tarefa de administração doméstica", Agamben (2011, p. 38) sustenta que, desconsiderando-se infrequentes e supostas exceções, o léxico paulino é propriamente "econômico" e "não político", e que os cristãos são, nesse sentido, "os primeiros homens integralmente econômicos”. Explica ele:

Paulo não só se refere, no sentido que assinalou, a uma oikonomia de
Deus, mas também se refere a si mesmo e aos membros da comunidade
messiânica com termos que pertencem exclusivamente ao vocabulário da
administração doméstica: doulos ("escravo"), hyperetes, diakonos ("criado"),
oikonomos ("administrador"). O próprio Cristo (ainda que o nome seja
sinônimo de soberano escatológico) é definido sempre com o termo que
designa o dono do oikos (kyrios, em latim, dominus) e nunca os termos mais
diretamente políticos anax ou archon (o apelativo não devia ser indiferente:
sabemos por Irineu que os gnósticos se negavam a chamar o Salvador de
kyrios e, por outro lado, usavam o termo político "arconte" para designar as
figuras divinas do pleroma). (AGAMBEN, 2011, p. 37-38).

O autor assinala a ocorrência de uma fragilização progressiva da oposição aristotélica entre oîkos e pólis desde o período helenístico, de modo que o texto paulino é um reflexo desse processo de "mutação semântica" derivado do intercurso entre o vocabulário político e o econômico, mormente na era romana imperial. Mas Agamben (2011, p. 39) acredita que o apóstolo "imprime a esse processo uma nova aceleração, que permeia todo o registro metaforológico do léxico cristão", à medida, por exemplo, que a comunidade cristã é muitas vezes referida como "oîkos de Deus" e não pólis (ou seja, como "casa" e não "cidade"). A esse respeito, os cinco textos mencionados e seu comentário correspondente são os seguintes:

Mas, se tardar, para que saibais como convém andar na casa de Deus [oiko theou], que é a igreja do Deus vivo [ekklesia theou zontos], a coluna e firmeza da verdade. (1 Timóteo 3:15, BíBLIA, 2007, p. 1295).

Do qual todo o corpo [soma], bem ajustado, e ligado pelo auxílio de todas as juntas, segundo a justa operação de cada parte, faz o aumento do corpo para sua edificação [oikodomen] em amor. (Efésios 4:16. BíBLIA, 2007, p. 1274)

Sigamos, pois, as coisas que servem para a paz e para a edificação [oikodomes] de uns para com os outros. (Romanos 14:19. BíBLIA, 2007, p. 1233)

Mas o que profetiza fala aos homens para edificação [oikodomen], exortação e consolação. (1 Coríntios 14:3, BÍBLIA, 2007, p. 1248)

Cuidais que ainda nos desculpamos convosco? Falamos em Cristo perante Deus, e tudo isto, ó amados, é para vossa edificação [oikodomes]. (2 Coríntios 12:19, BÍBLIA, 2007, p. 1263) 
Exemplos significativos são o uso de oîkos para em $1 \mathrm{Tm} 3$,15, em que a comunidade é definida como "casa [não 'cidade'] de Deus" [oikos theou] e de que oikodome e oikodomeo (termos referentes à construção da casa) no sentido "edificante" de construção da comunidade (Ef 4,16; Rm 14,19; 1 Cor 14,3; 2 Cor 12,19). Que a comunidade messiânica seja representada desde o início nos termos de uma oikonomia, e não naqueles de uma política, é um fato cujas implicações para a história da política ocidental ainda restam a ser discutidos. (AGAMBEN, 2011, p. 39).

Sobre o texto de 1 Timóteo 3:15, percebe-se que ao ser representada como oîkos ("casa") a comunidade messiânica não é, necessariamente, representada "nos termos de uma oikonomia", é dizer: a habitação, o espaço de associação familiar e de vida doméstica não corresponde, única e imediatamente, ao aspecto gerencial que contém. Mais ainda, note-se que Paulo diz, ali, que a oîkos ("casa”) é a ekklesía ("assembleia”, "igreja”) de Deus, e não o contrário. De igual modo, tendo em vista o contexto histórico da associação entre os primeiros cristãos, sabe-se que, à medida que uma comunidade de crentes reunia-se regularmente em um espaço físico, enquanto tal ele tornava-se o espaço de culto dessa comunidade - uma "casa de Deus" (ou ainda, "para Deus"). Na breve carta que envia a Filemon, por exemplo, Paulo estende sua saudação à Áfia, a Árquipo "e à igreja que está em tua casa [kat oikon sou ekklesia]" (versículo 2 do capítulo 1 ). Igual construção se faz presente também em 1 Coríntios 16:19 e Colossenses 4:15.

Vê-se, por conseguinte, que a comunidade messiânica não é representada nos termos de uma oikonomia, mas comparece propriamente como ekklesía. Já em Efésios, como também ocorre em 1 Timóteo 1, 3-4 (ver acima) a fortificação espiritual mútua entre os membros da ekklesía é apresentada por uma dupla analogia, anatômica (soma) e arquitetônica (oikodomia), e é a última dessas figuras que reaparece nos demais textos dessa parte da análise de Agamben.

Deve-se ressaltar, novamente, que os textos paulinos são tencionados pela oposição e complementariedade que existe entre a realidade espiritual e a ordem secular - política e econômica, pública ou privada. Na carta aos Coríntios, por exemplo, Paulo pondera os benefícios e os desafios espirituais do casamento. A vida doméstica é colocada em claro contraste com os encargos divinos em trechos como este: "E bem quisera eu que estivésseis sem cuidado; o solteiro cuida das coisas do Senhor, em como há de agradar ao Senhor; mas o que é casado cuida das coisas do mundo, em como há de agradar à mulher" (1 Coríntios 7:32-33, BíBLIA, 2007, p. 1242). Ao mesmo tempo, em outro de seus textos o bom governo 
da casa por parte do pai serve como uma miniatura para se avaliar suas capacidades como bispo na assembleia de crentes: "Que [o bispo] governe bem a sua própria casa, tendo seus filhos em sujeição, com toda a modéstia. (Porque, se alguém não sabe governar a sua própria casa, terá cuidado da igreja de Deus?)" (1 Timóteo 3:4-5, BÍBLIA, 2007, p. 1294).

As relações complexas entre o cristão e a pólis também não escapam ao olhar atento de Paulo. Em Efésios 1:17-21, o apóstolo deseja que Deus dê à igreja "o espírito de sabedoria e revelação" que permite reconhecer que o Filho de Deus, ressurreto, foi posto pelo Pai "acima de todo o principado, e poder, e potestade, e domínio, e de todo o nome que se nomeia, não só neste século, mas também no vindouro" (BÍBLIA, 2007, p. 1271). Isso ajuda a entender a justificativa que Paulo apresenta em Romanos 13:1-7 e 1 Timóteo 2:1-4 para a existência dos poderes seculares; bem como a necessidade dos cristãos estarem submissos aos mesmos (desde e sempre que eles não imponham a observância de leis contrárias aos mandamentos de Deus).

Todas essas considerações permitem dizer, então, que, ao passo que Agamben vê em Paulo a "nova aceleração" de uma tendência histórica de enfraquecimento da tensão aristotélica entre a ordem política e a prática doméstica, como já foi sugerido acima, tal posição deve ser reexaminada, por estar fundamentada em um pretenso abrandamento da tensão entre o apóstolos e o oikonómos. Por conseguinte, ficam inteiramente ausentes as bases sobre as quais o autor assenta que os cristãos do tempo de Paulo são "os primeiros homens integralmente econômicos". Tanto nas epístolas paulinas como em Aristóteles, a vida econômica e material não recebe proeminência sobre outras esferas. É instrutivo, a esse respeito, o uso comum de metáfora anatômica para expressar a unidade de seus centros da vida humana na terra - da ekklesía, no caso de Paulo, e da pólis, no caso de Aristóteles. Esse último, ao introduzir a Política, escreve:

As sociedades domésticas e os indivíduos não são senão as partes integrantes da Cidade, todas subordinadas ao corpo inteiro, todas distintas por seus poderes e suas funções, e todas inúteis quando desarticuladas, semelhantes às mãos e aos pés que, uma vez separados do corpo, só conservam o nome e a aparência, sem a realidade, como uma mão de pedra. O mesmo ocorre com os membros da Cidade: nenhum pode bastarse a si mesmo. Aquele que não precisa dos outros homens, ou não pode resolver-se a ficar com eles, ou é um deus, ou um bruto. (ARISTÓTELES, 1944 , v. 21, seção 1253a). 
Similarmente, Paulo aconselhará em 1 Coríntios 12:25-27 "que não haja divisão no corpo, mas antes tenham os membros igual cuidado uns dos outros". Dessa maneira, escreve ele, "se um membro padece, todos os membros padecem com ele; e, se um membro é honrado, todos os membros se regozijam com ele. Ora, vós sois o corpo de Cristo, e seus membros em particular" (BÍBLIA, 2007, p. 1247).

Finalmente, importa recordar que, quando Agamben (2011, p. 15) sugere que "a vida eterna que o cristão reivindica reside, em última análise, sob o paradigma do oikos e não sob o da polis", parece ignorar versos como o da carta aos Hebreus 11:10, no qual os que aguardaram a vinda do reino do Messias são lembrados como os que esperam "a cidade que tem fundamentos, da qual o artífice e construtor é Deus", a eternal Nova Jerusalém (BíBLIA, 2007, p. 1315).

\section{CONSIDERAÇÕES FINAIS}

O presente artigo atendeu a uma sugestão do próprio Agamben (2005, p. 11), de "não menosprezar a teologia" e apresentou uma releitura dos trechos de Paulo citados em $O$ Reino e a Glória. Essa releitura evidenciou que (1) tais trechos demonstram claramente uma manutenção do sentido clássico, do paradigma gerencial da oikonomia, entendida, também, como a atividade de dispor um material de modo ordenado, orientado a um fim - sendo isso o que, ademais, permite sua extensão analógica; (2) que a oikonomia não se identifica com um encargo espiritual propriamente dito, embora possa the representar em algumas passagens, ou seja, Paulo é antes um apóstolo do que um oikonómos; e, finalmente, (3) que não se justifica a afirmação de que, com Paulo, "a comunidade messiânica é representada nos termos de uma oikonomia". Assim, fica evidente a necessidade de que Agamben também seja avaliado por seus leitores como aconselha Paulo, "comparando as coisas espirituais com as espirituais" (1 Coríntios 2:13, BíBLIA, 2007, p. 1237). 


\title{
THE OIKONOMIA IN EPISTLES OF PAUL: NOTES ON AGAMBEN'S "HERMENEUTICS"
}

\begin{abstract}
:
Accompanying the genealogy of the theological concept of oikonomia, which Giorgio Agamben offers in The Kingdom and the Glory, the article proposes a rereading of passages in which the Apostle Paul, in his letters to the churches, uses this Greek term. This rereading essentially confirms the general proposition of Agamben that the understanding of oikonomia as "management" of men and things does not seem to have suffered significant semantic changes in Paul's writings and in the language current among Christians of the second century. However, this rileggere ultimately indicates no insignificant weaknesses in The Kingdom and the Glory, which can be found both by a not-specialized reader and by scholars in philosophy, theology and political economy. These notes on Agamben's work also attempt to establish a dialogue with other texts recently published in Brazil about him, the Italian philosopher.
\end{abstract}

Keywords: Oikonomia. Epistles of Paul. Hermeneutics. Giorgio Agamben. The Kingdom and The Glory.

\section{LA OIKONOMÍA EN LAS EPÍSTOLAS DE PABLO: NOTAS SOBRE LA "HERMENÉUTICA" DE AGAMBEN}

\section{Resumen:}

Acompañando la genealogía del concepto teológico de oikonomia, que Giorgio Agamben ofrece en su obra El Reino y la Gloria: Por una Genealogia Teológica de la Economia y del Gobierno, el artículo propone una relectura de los pasajes en los cuales el apóstol Pablo, en sus cartas a las iglesias, usa el término griego. Esta relectura confirma la proposición general del filósofo italiano, que la comprensión de oikonomia como "administración" de los hombres y las cosas - es decir, como un paradigma de gestión - no parece haber sufrido cambios semánticos significativos en los escritos de Pablo o en el lenguaje de los cristianos del segundo siglo. Sin embargo, esta relectura termina por indicar fragilidades no despreciables en El Reino y la Gloria, las cuales pueden ser constatadas tanto por el lector no especializado como por los estudiosos de Agamben en los campos de la filosofía, de la teología y de la economía política. Estas notas sobre la obra de Agamben son, por fin, un intento de establecer diálogo con otros textos publicados recientemente en Brasil sobre el filósofo italiano.

Palabras Clave: Oikonomia. Epístolas de Pablo. Hermenéutica. Giorgio Agamben. El Reino y la Gloria. 


\section{REFERÊNCIAS}

AGAMBEN, G. "A Europa Precisa Colapsar" In: SARAIVA, M. H. Entrevista com Giorgio Agamben, por Iris Radisch (Tradução). Profanações, Ano 3, n. 1, p. 238248, 2016.

. "Cristianismo como Religião: a Vocação Messiânica”. In: SBARDELOTTO, M. Adaptação de um discurso de Agamben na Catedral de Notre-Dame, em Paris, em março de 2009 (Tradução). Publicada em 16 Julho de 2013. Disponível em: <https://blogdaboitempo.com.br/2013/07/16/cristianismo-como-religiao-a-vocacaomessianica/ >. Acesso em: 29 set 2016.

. "Da Teologia Política à Teologia Econômica". In: ASSMANN, S.J. Entrevista com Giorgio Agamben, por Gianluca Sacco (Tradução). Revista Internacional Interdisciplinar INTERthesis, v. 2, n. 2, p. 1-11, 2005.

. O Mistério do Mal. Bento XVI e o Fim dos Tempos. Tradução de Silvana de Gaspari e Patrícia Peterle. São Paulo: Boitempo; Florianópolis, SC: Ed. da UFSC, 2015.

O Reino e a Glória: uma Genealogia Teológica da Economia e do Governo: Homo sacer, II, 2. São Paulo: Boitempo, 2011.

ARISTÓTELES. Aristotle in 23 Volumes. Tradução de Harris Rackham. Cambridge: Harvard University Press; Londres, William Heinemann Ltd, 1944. Disponível em:

<www.perseus.tufts.edu/hopper/text?doc=Perseus:text:1999.01.0058>. Acesso em: 29 set 2016.

ASSMANN, S. J. O Romano Radical (Entrevista). Subtrópicos, n. 17, p. 6-7, 2015.

BÍBLIA. Grego. Novum Testamentum Textus Stephanici a.D. 1550. Whitake et soc.; G. Bell et filli: Londres, 1877.

Português. Bíblia Sagrada. Tradução de João Ferreira de Almeida. Edição Corrigida e Revisada Fiel ao Texto Original. São Paulo: Sociedade Bíblica Trinitariana do Brasil, 2007.

GIGNAC, A. Paulo de Tarso e os Filósofos Contemporâneos. In: NEUTZLING, I. (ed). Cadernos IHU em Formação. Ano 5, n. 32, p. 12-24, 2009. 
HARDEN, J.M. Dictionary of the Vulgate New Testament. Londres: Society for Promoting Christian Knowledge. Nova Iorque: Macmillan Co, 1921.

HARINK, D. (ed). Paul, Philosophy and the Theopolitical Vision: Critical Engagements with Agamben, Badiou, Zizek and Others (Theopolitical Visions 7). Eugene: Cascade Books, 2010.

KEREKES, E. The Figure of the Apostle Paul in Contemporary Philosophy (Heidegger, Badiou, Agamben, Žižek). Journal for the Study of Religions and Ideologies, v. 14, n. 42, p. 27-53, 2015.

MCCLOSKEY, D. N. The Two Movements in Economic Thought, 1700-2000: Empty Economic Boxes Revisited. 2016. Disponível em: <http://deirdremccloskey.org/docs/pdf/CataniaSpeech2016.pdf >. Acesso em: 20 set 2016.

MILOVIC, M. Política do Messianismo: algumas reflexões sobre Agamben e Derrida. Cadernos de Ética e Filosofia Política, n. 14, p. 103-121, 2009.

RATAJCZAK, M; ZAWISZA, R. Introduction: Theology as a Critique. Praktyka Teoretyczna, n. 3, v. 17, p. 8-22, 2015.

SCHUMPETER, J. A. História da Análise Econômica, v. 1. Rio de Janeiro: Fundo de Cultura, 1964.

TEIXEIRA, A. Marx e a Economia Política: a Crítica como Conceito. Econômica, v. 2, n. 4, p. 85-109, 2000.

\section{Artigo:}

Recebido em 30 de Setembro de 2016.

Aceito em 10 de Junho de 2017. 